\title{
DESNUDAMENTO DO TOTALITARISMO NUMA VISÃO ARENDTIANA: ESTRUTURAS DO ONTEM, DO HOJE PARA UM NÃO-AMANHÃ
}

\author{
Carlos Fernando Silva Brito
}

RESUMO: A sociedade hodierna fora marcada exclusivamente pelos eventos ocorridos no século XX, de modo especial pelos horrores das duas Guerras Mundiais. Tais acontecimentos deixaram legados para a sociedade hodierna, e estes legados só podem ser enxergados a partir da tomada de conhecimento daquilo que foi a estrutura do totalitarismo. Visando esclarecer a cerca de tais estruturas o presente artigo baseado na obra de Hannah Arendt, e nos comentários de Cristina Ribas e Celso Lafer desenvolverá um leve esboço de estruturas básicas do referido regime. Numa posição propositiva ter-se-á que ao fim do artigo questionamentos serão deixados como pistas para a reflexão sobre a sociedade brasileira aos futuros leitores da obra de Arendt.

Palavras-chave: Arendt; Totalitarismo; Estruturas totalitárias.

\section{UNDERSTANDING TOTALITARISM IN AN ARENDRIAN VISION: STRUCTURES OF THE TODAY, FROM TODAY TO A NON-TOMORROW}

\begin{abstract}
Today's society is marked exclusively by occós events in the twentieth century, especially by the horrors of the two World Wars. Such events have left legacies for a modern society, and these legacies can only be seen from the taking of knowledge of what is a structure of totalitarianism. In order to clarify some of these structures in the present article in the work of Hannah Arendt, in the works of Cristina Ribas and Celso Lafer, we have developed a slight outline of the structures of this regime. In a propositional position, the question is what the end of the article questioning is left as a clue to a reflection on a Brazilian society to the future readers of Arendt's work.
\end{abstract}

Keywords: Arendt; Totalitarianism; Totalitarian structures.

\section{INTRODUÇÃO}

No século XX a humanidade, como um todo, se foi abalada psicológica, moral e estruturalmente em todos os âmbitos, a saber, sociais, culturais e espirituais pelo evento da Segunda Grande Guerra Mundial, evento este, que até os dias atuais marca algumas formas de pensar e de agir na sociedade contemporânea. 
Ao longo da história, como é sabido, a filosofia sempre buscou refletir e propor respostas a problemas emergentes, aqui vale destacar que a $2^{\circ}$ Guerra mundial não se faz exceção a essa "regra". Através de alguns filósofos viventes desse período buscou-se se desmistificar e desvendar a realidade do sistema que gerara milhões de mortes. Dentre estes filósofos, destaca-se a figura de Hannah Arendt, judia e filósofa política que nascera em Hanover (Alemanha) em 1906 e morrera em 1975 nos Estados Unidos. Arendt como muitos intelectuais da sua época, fora vítima dos horrores nazistas, tendo estado como prisioneira em campo de concentração e passando boa parte de sua vida como refugiada na França e apátrida nos Estados Unidos da América.

Todo o pensamento político arendtiano é mergulhado no contexto da $2^{\circ}$ Guerra Mundial, mais precisamente no problema do regime totalitário do nazismo. Deste modo, como nos afirma Ribas, "Compreender o impacto do totalitarismo na vida de Arendt, é indispensável, uma vez que, para ela, o pensamento deve estar sempre ligado à experiência concreta da qual emerge" ${ }^{2}$.

Todas as suas obras giram em torno da ruptura inaugurada pelo totalitarismo, destarte conhecer o seu contexto é intrínseco a tentativa de compreender seu pensamento, sendo assim, fazer-se-á aqui não um estudo aprofundado sobre a história do totalitarismo, mas, sim um leve esboço daquilo que Arendt esclarece como sendo a estrutura dum "Inferno".

\section{ESTRUTURAS DO SISTEMA TOTALITÁRIO}

\section{Totalitarismo e a sociedade}

Todo governo, seja ele tirânico, despótico ou totalitário precisa das massas para manter-se firme, e perpetuar a sua ideologia. Refletindo sobre a importância da sociedade para o totalitarismo Arendt afirma que este, “[...] não poderia ter mantido a liderança de tão grande população, sobrevivido a tantas crises internas e externas, e enfrentado tantos perigos de lutas intrapartidárias, se não tivesse contado com a confiança das massas.” ${ }^{3}$.

\footnotetext{
${ }^{1}$ Graduado em Filosofia pelo Instituto de Estudos superiores do Maranhão (IESMA), Especialista em ética e filosofia política pela UnYleYa, Mestrando em Filosofia pela Universidade Federal do Piauí. Contato: semfernand@gmail.com

${ }^{2}$ RIBAS, Cristina Miranda. Justiça em tempos sombrios: a justiça no pensamento de Hannah Arendt. Ponta Grossa: Ed. UEPG, 2005. P, 21.

${ }^{3}$ ARENDT, Hannah. Origens do totalitarismo. Trad. Roberto Raposo. São Paulo: Companhia das letras, 2012. $\mathrm{P}, 435$.
} 
Em Arendt o totalitarismo se destaca de outros regimes governamentais justamente porque este dá uma grande ênfase para o papel das massas, transformando-as em condicionante sine qua non para sua existência. No entanto é necessário fazer uma distinção entre movimento totalitário e governo totalitário. Para isto, Arendt afirma:

Somente onde há grandes massas supérfluas que podem ser sacrificadas sem resultados desastrosos de despovoamento é que se torna viável o governo totalitário, diferente do movimento totalitário. Os movimentos totalitários são possíveis onde quer que existam massas que por um motivo ou outro, desenvolveram certo gosto pela organização política. ${ }^{4}$.

Em suma a diferença básica entre movimento e governo se dá pelo fato de que no movimento totalitário o seu principal armamento é a propaganda, pois este se forma em um meio que não é totalitário, as massas neste aspecto, são almejadas pela fidelidade. Já no governo totalitário a principal característica é o terror, que serve como coerção a fim de manter o poder. Já nesta fase o objetivo é a permanência da fidelidade das massas.

A sociedade é o palco onde se desenvolve as ideias totalitaristas. O importante papel da sociedade neste movimento se da pela sua influência que esta dará para a perpetuação do movimento. Não há totalitarismo se não houver domínio das massas.

\section{O princípio de liderança e a propaganda.}

O movimento totalitário, como fora destacado acima, caracteriza-se pelo domínio das massas, domínio este que se dá através do uso da propaganda. Esta é "tão franca quanto mentirosa" 5 . A propaganda totalitária é repleta de mentiras. Os discursos de Hitler eram "caracterizados principalmente pelas monstruosas mentiras", que quanto maiores fossem mais fáceis eram de ser aderidas.

Segundo Arendt, “[...] a propaganda é um [dos] instrumento [s] do totalitarismo, possivelmente o mais importante, para enfrentar o mundo não totalitário"7. Isso se dá porque o mundo não totalitário deverá tomar conhecimento do movimento para poder aderir, e por esse fato não há uma doutrinação de ideais e sim uma propagação através do anúncio comercial desta "mercadoria".

\footnotetext{
${ }^{4}$ Ibid. p, 438.

${ }^{5}$ Ibid. p, 435.

${ }^{6}$ Ibid. p, 475.

${ }^{7}$ Ibid. p, 476.
} 
Como afirma Arendt, "O sucesso da propaganda totalitária não se deve tanto à sua demagogia quanto ao conhecimento de que o interesse, como força coletiva, só se faz sentir onde um corpo social estável proporciona a necessária conexão motora entre o indivíduo e o grupo" ${ }^{",}$ ou seja, só terá sucesso à propaganda se houver a necessidade dos indivíduos de se agruparem, a propaganda não é persuasiva e sim organizativa.

O movimento totalitário tem também como base o princípio de liderança, que consiste "unicamente da posição em que o movimento, graças à sua peculiar organização, coloca o líder, ou seja, da importância funcional do líder." 9 . O líder no movimento totalitário é insubstituível, pois é de sua mão que toda a complicada estrutura do movimento deriva. Sem ele essa estrutura perderia sua raiz e seu foco.

O líder totalitário não se deve confundir com um tirano, para tanto Hannah Arendt diferenciando-os nos diz que,

Um tirano jamais se identificaria com os seus subordinados, e muito menos com cada um dos seus atos; poderia usá-los como bodes expiatórios, deixando, com prazer, que fossem criticados para colocar-se a salvo da ira do povo, mas sempre manteria uma distancia absoluta de todos os seus subordinados e súditos. O Líder, ao contrário, não pode tolerar críticas aos seus subordinados, uma vez que todos agem em seu nome; se deseja corrigir os próprios erros, tem que liquidar aqueles que os cometerem por ele; se deseja inculpar os outros por esses erros, tem de mata-los. 10

Nessa estrutura o que os difere é exatamente a sua relação com os seus subordinados. Enquanto o tirano dá aos seus subordinados a liberdade de agirem por conta própria visando os interesses da tirania. No totalitarismo todos agem em nome do Líder, e por isso todo erro pode ser considerado como fraude, pois, a ordem é expressa diretamente ao sujeito pelo Líder. Por isso, o Líder se responsabiliza pelos seus, enquanto que o tirano, os da certa independência.

\section{O governo totalitário}

Fazendo uso da reflexão de Lafer, sobre a obra de Arendt, destaca que "[...] o que caracteriza a gestão [governo] totalitária é o primado do movimento. Este primado do

\footnotetext{
${ }^{8}$ Ibid. p, 481.

${ }^{9}$ Ibid. p, 500.

${ }^{10}$ Ibid. p, 511. (Grifo meu)
} 
movimento é necessário para que o mundo, no dia a dia, não adquira a normalidade que advém da estabilização que as leis e as instituições oferecem"11.

O que Lafer e Arendt, querem dizer, é que o Líder deverá conservar um constante movimento de cargos na estrutura do governo, afim de que o mesmo não se torne como outros, um lugar de estagnação de pessoas que passarão a agir por falsidade.

A fim de conseguir tal façanha, o líder aplica a duplicação de cargos, que para estes era uma questão de princípio, e não apenas artifício destinado a criar empregos para os membros do partido. Essa multiplicação de órgãos era extremamente útil para a constante transferência do poder, segundo Arendt, "quanto mais tempo um regime totalitário permanece no poder maiores se tornam o número de órgãos e a possibilidade de empregos que dependem exclusivamente do movimento, uma vez que nenhum órgão é abolido quando a sua autoridade é liquidada" ${ }^{12}$. O governo totalitário é na verdade um amontoado de estruturas, que apesar de perderem sua eficiência, não são destruídas, pois permanecem na base de aliança do líder. Isso ocorre a fim de evitar revoltas.

"Quanto mais visível o poder do totalitarismo, mais secretos são os seus verdadeiros objetivos" ${ }^{13}$, afirma Arendt. Isso se faz entender a partir da metáfora da cebola usada por Arendt para descrever a relação da estrutura com o princípio da invisibilidade. Segundo ele,

[...] a imagem mais adequada para a sociedade, o Estado e o Direito nos regimes totalitários não é a tradicional pirâmide, mas sim a de uma cebola. No centro, numa espécie de vazio, localiza-se o líder. Tudo o que faz, ele o faz de dentro, não de fora ou de cima. [...] Quanto mais próximo do centro da cebola, maior é o segredo e o poder. ${ }^{14}$

O poder parte do centro da "cebola" em direção à parte externa, ou seja, o Líder é o mais consciente dos atos de todos, consequentemente quanto mais próximo dele maior a consciência e maior ainda a necessidade de resguardar o segredo dos "verdadeiros objetivos".

Outro aspecto do governo totalitário é a realização plena de seu objetivo, chamada de 'Campo de concentração'. Estes são a verdadeira instituição central do poder

\footnotetext{
${ }^{11}$ LAFER, Celso. A reconstrução dos direitos humanos: um diálogo com o pensamento de Hannah Arendt. São Paulo: Companhia das letras, 1988. P, 131.

12 Ibid. P, 539.

${ }^{13}$ Ibid. P, 553

${ }^{14}$ LAFER, Celso. op. cit. 1988. P, 133.
} 
organizacional. Eles são o modelo social perfeito para o domínio total geral ${ }^{15}$. Nesse aspecto Lafer faz um resumo da atividade do campo de concentração no regime totalitarista escrevendo que estes são:

(I) o laboratório que demonstra a convicção totalitária de que tudo é possível; (II) o lócus que permite não apenas o extermínio físico das pessoas, mas também a eliminação da espontaneidade como dimensão e expressão da conduta humana e, consequentemente, o ambiente que verdadeiramente permite a transformação da personalidade humana numa simples coisa; e (III) a instituição essencial para a preservação do poder do regime pelo medo indefinido que os campos de concentração inspiram na sociedade e pelo treinamento muito definido que oferecem em matéria de dominação total, que em nenhuma parte, a não ser no isolamento dos campos, pode ser testado em todas as suas radicais possibilidades ${ }^{16}$.

Arendt destaca que o Campo de concentração é uma realidade extraterreste. Por isso usa a metáfora para descrever que este pode se classificar em três tipos. Primeiro em "Limbo, onde se encontra os refugiados, os apátridas, os marginais e os desempregados", segundo em "Purgatório, são representados pelos campos de trabalho da União Soviética, onde o abandono alia-se ao trabalho forçado e desordenado", e por ultimo o "Inferno, é representado por aquele tipo de campo que os nazistas aperfeiçoaram e onde toda vida era organizada, completa e sistematicamente, de modo a causar o maior tormento possível" ${ }^{17}$.

O 'Inferno' é, pois o único lugar que é possível as três morte dos humanos, a saber, a jurídica (perder proteção de uma nação), a morte moral (aqui não escolhe entre o bem e o mal e sim entre matar e matar, este serve para a polícia nazista) e a morte individual (destruir a espontaneidade, a capacidade do homem de iniciar algo novo).

O totalitarismo é por fim na sua essência o terror. E funciona por princípios lógicos e estruturais. É a plena realização da passagem dos governos tirânicos e imperialistas onde "tudo é permitido" para o governo novo onde "tudo é possível" 18.

\section{CONCLUSÃO: perpetuação de estruturas totalitárias.}

É impossível passar por esta análise sem refletir sobre a perpetuação desse sistema em alguns artífices da sociedade atual. Arendt empenhou-se numa empreitada rumo à

\footnotetext{
${ }^{15}$ ARENDT, Hannah. op. cit. 2012. P, 582-3.

${ }^{16}$ LAFER, Celso. op. cit. 1988. P, 143.

${ }^{17}$ ARENDT, Hannah. op. cit. 2012. P, 591.

${ }^{18}$ LAFER, Celso. op. cit. 1988. P, 148.
} 
desmistificação do sistema totalitário, que no fim, por ser bem sucedia, rendeu-lhe fama e prestígio social, mas que acima de tudo serviu como base para outros pensarem as estruturas políticas das sociedades no pós-guerra.

Seu pensamento é um convite ao diálogo, um convite a um repensar sobre o pensar estrutural de sistemas desumanos que aprisionam e destroem os homens. Infelizmente ainda hoje não houve a libertação completa de algumas das amarras dessas estruturas. A política brasileira sofre com "aprendizes" de nazistas que usam artifícios totalitários para galgar o poder.

Ou será que a mentira totalitária ou a propaganda totalitária ainda hoje não seria o grande artífice de alguns políticos brasileiros? Ou ainda, será que o desejo de manipular as massas menos esclarecidas já deixou de ser alvo da política brasileira? E não podemos esquecer-nos do principio de movimento e do princípio de invisibilidade, que alguns tentam a todo custo preservar através de segredos partidários, que muitas vezes nem mesmo os membros possuem o esclarecimento sobre o que de fato de engendra nos gabinetes brasilienses.

Por fim, destaca-se que estas questões são hoje possibilidades de reflexões para leitores, ou não, do conjunto da obra arendtiana. São problemas emergentes que mais uma vez precisarão de filósofos para dar caminhos de reflexão e possibilidades de soluções. Do contrario, não hoje, mas em algum dia futuro, poderemos ser vítimas de uma prépersonificação daquilo que Arendt chamara de "Inferno".

\section{REFERÊNCIAS}

ARENDT, Hannah. Origens do totalitarismo. Trad. Roberto Raposo. São Paulo: Companhia das letras, 2012.

LAFER, Celso. A reconstrução dos direitos humanos: um diálogo com o pensamento de Hannah Arendt. São Paulo: Companhia das letras, 1988.

RIBAS, Cristina Miranda. Justiça em tempos sombrios: a justiça no pensamento de Hannah Arendt. Ponta Grossa: Ed. UEPG, 2005. 